\title{
O DISCURSO ORGANIZACIONAL SOBRE COMUNICAÇÃO FACE A FACE E O SILENCIAMENTO CORPORATIVO
}

\author{
Organizational discourse about face-to-face communication and corporate \\ muting
}

\author{
El discurso organizacional sobre la comunicación cara a cara y el \\ silenciamiento corporativo
}

Ana Maria Dantas de Maio Doutora em Comunicação Social, jornalista da Embrapa Pecuária Sudeste anamaio@uol.com.br

\section{Resumo}

Este artigo propõe um olhar crítico para o discurso sobre a comunicação face a face e busca desvendar o uso que se faz de suas propriedades positivas para sustentar interesses organizacionais. Com suporte teórico-metodológico da análise de discurso da escola francesa, o objetivo é avaliar a apropriação das vantagens dessa modalidade de comunicação por parte das organizações. A corporação em análise é a norte-americana Yahoo, que em 2013 proibiu a prática do home-office, procurando estimular a convivência face a face entre seus empregados. O discurso organizacional é estudado em sintonia com o discurso jornalístico que divulgou a informação. Além dos gêneros discursivos, o trabalho avalia os silenciamentos da mídia e da organização.

Palavras-chave: Comunicação face a face. Comunicação organizacional. Yahoo.

\begin{abstract}
This article proposes a critical look at the discourse about face-to-face communication and attempts to unveil the use that is made of its positive features in order to sustain corporate interests. Based on the theoretical-methodological support of French-school discourse analysis, it aims at evaluating the appropriation of advantages of this mode of communication on the part of organizations. The corporation under scrutiny is Yahoo, from North America, which in 2013 banned home-office practice, trying to stimulate face-to-face conviviality among its employees. The organizational discourse is studied in consonance with the journalistic discourse that disclosed it. Besides evaluating the discourse genres, this article also focuses on corporate and media muting.
\end{abstract}

Key words: Face-to-face communication. Corporate communication. Yahoo. 


\section{Resumen}

Este artículo propone una mirada crítica hacia el discurso sobre la comunicación cara a cara y busca desvendar el uso que se hace de sus propiedades positivas para sostener intereses organizacionales. Con el soporte teórico-metodológico del análisis del discurso de tradición francesa, el objetivo es evaluar la apropiación de las ventajas de esta modalidad de comunicación por parte de las organizaciones. La empresa que hemos analisado es la norteamericana Yahoo, que en el 2013 prohibió la práctica de home-office, buscando estimular la convivencia cara a cara entre sus empleados. El discurso organizacional lo hemos estudiado en sintonía con el discurso periodístico que propaló la información. Además de los géneros discursivos, el trabajo evalúa los silenciamientos de los Media y de la organización.

Palabras clave: Comunicación cara a cara. Comunicación organizacional. Yahoo.

\section{INTRODUÇÃO}

Este artigo propõe uma reflexão crítica a respeito do discurso organizacional sobre comunicação face a face no ambiente corporativo. O objetivo é verificar até que ponto esse discurso pode estar mascarando intencionalidades empresariais. Contradições entre o dito, o não-dito e distintas formas de dizer serão observadas pela Análise de Discurso (AD) da escola francesa sobre uma polêmica envolvendo a empresa norte-americana de tecnologia da informação Yahoo. Em 2013 a organização decidiu eliminar a prática do home-office, ou seja, a possibilidade de os funcionários trabalharem em casa, alegando que fisicamente juntos os resultados teriam mais qualidade. Contrária à medida, parte da mídia se manifestou sugerindo que a decisão poderia estar escondendo uma manobra corporativa para forçar funcionários a pedir demissão de forma voluntária, reduzindo os altos custos da organização.

$\mathrm{O}$ artigo começa com a apresentação de informações sobre a Yahoo, sua cultura organizacional e o perfil de sua principal executiva, Marissa Mayer, colhidos a partir de uma publicação biográfica lançada em janeiro de 2015 nos Estados Unidos e em novembro do mesmo ano no Brasil. Em seguida é exposto o embasamento teórico sobre a análise de discurso, destacando os pensamentos de Michel Pêcheux (2014), Eni Orlandi (2007, 2012) e Dominique Mainguenau (2004a, 2004b), entre outros estudiosos da AD, além de Mikhail Bakhtin (1984, 1997), teórico da linguagem.

Durante o procedimento de análise do caso Yahoo, duas especificidades serão abordadas: a noção de gêneros de discurso e as diferentes formas de silêncio, que se mostram determinantes para a compreensão discursiva. Essa reflexão faz parte da tese de doutorado " $\mathrm{O}$ 
papel da comunicação face a face nas organizações no contexto da sociedade midiatizada", defendida por esta autora na Universidade Metodista de São Paulo em fevereiro de 2016.

\section{SUPORTE TEÓRICO-METODOLÓGICO}

A abordagem teórico-metodológica da Análise de Discurso (AD) permite conhecer o funcionamento de textos e construir sentidos relacionados aos discursos organizacionais. Textos jornalísticos - incluindo a íntegra de um comunicado organizacional - que abordam o fim do home-office na empresa Yahoo fazem parte do corpus desta pesquisa. $\mathrm{O}$ discurso da empresa para seus funcionários, sob a perspectiva da mídia, tornou-se público no início de 2013, quando a companhia comunicou a seus 15 mil empregados em todo o mundo que a partir de junho daquele ano todas as atividades profissionais deveriam ser desenvolvidas nos escritórios - em situação face a face -, e não mais em casa. A notícia repercutiu em vários países, inclusive no Brasil, onde o home-office tem sido adotado por diversas organizações.

Foi selecionado um conjunto de matérias jornalísticas, publicadas em sites especializados em empregos e carreiras durante dois momentos distintos: início de 2013, quando a empresa anuncia a decisão, e entre o final de 2014 e início de 2015, em uma tentativa de atualização dos dados. O silêncio instituído no intervalo entre esses dois momentos também será objeto de estudo.

A análise de discurso vai privilegiar a linguagem, a contextualização e as intencionalidades que podem estar por trás de um apelo ao "trabalhar juntos". A pesquisa bibliográfica desponta como metodologia natural para a elaboração do artigo.

\section{DESCOLADA OU FECHADA?}

A polêmica relacionada à eliminação da prática do home-office pela Yahoo apresenta como pano de fundo a filosofia de trabalho da organização e as ações implementadas por sua principal executiva, Marissa Ann Mayer. Se por um lado a Yahoo pode ser considerada uma organização dinâmica, “descolada" e respeitada, por outro ela é descrita como uma empresa sem foco de atuação, burocrática, fechada e instável. É o que transmite o biógrafo Nicholas Carlson (2015).

Desde que foi criada, a organização convivia com o debate sobre sua identidade no sentido de definir se deveria atuar como uma empresa de mídia, focada na produção e 
distribuição de conteúdo, ou uma empresa de produtos, direcionada a desenvolver ferramentas de software para internet. Nesse cenário de indefinição, Carlson apresenta Marissa Mayer, apontada como uma celebridade do mundo da tecnologia, que assumiu a empresa em 17 de julho de 2012. Ela era adepta da estratégia de que "a melhor maneira para o Yahoo se reinventar seria acompanhar a migração de PCs para celulares e se tornar realmente uma grande empresa de aplicativos" (CARLSON, 2015, p. 210).

Considerada tímida e socialmente pouco à vontade, Marissa é descrita como uma pessoa bastante ambiciosa. Carlson (2015, p. 135) comenta que "em geral, era vista como robótica ou arrogante. Sentia grande dificuldade em olhar as pessoas nos olhos". No entanto, sua competência técnica sempre foi amplamente reconhecida. Logo no início de sua gestão, a executiva implementou reuniões semanais com os yahoos (modo como os funcionários se tratam). Aceitava responder perguntas, inclusive anônimas.

Transformar a Yahoo no melhor lugar para se trabalhar foi um dos argumentos empregados por Marissa no comunicado interno em que anuncia o fim do home-office na empresa. A executiva foi muito criticada pela imprensa por adotar essa política e um debate mundial foi instituído pela mídia especializada. Havia o entendimento que a decisão da Yahoo poderia abrir um precedente para que outras organizações seguissem a mesma estratégia. De fato, pelo menos outras duas corporações anunciaram medida semelhante nos meses seguintes: as americanas Best Buy e Hewlett-Packard.

A Yahoo permaneceu calada diante das críticas e, aparentemente, não forneceu detalhes sobre a suspensão. Não foram localizadas informações sobre quantos funcionários seriam atingidos e quantos iriam optar por demissões voluntárias - caso não aceitassem trabalhar nos escritórios. A ausência de dados precisos e o alvoroço criado pela mídia sugeriam que o fim do home-office afetaria grande parcela dos empregados. Apenas em janeiro de 2015, na biografia de Carlson, aparecem os primeiros números envolvidos com a decisão. Dos 15 mil funcionários, 164 teriam sido afetados e apenas um teria sido demitido por não comparecer ao trabalho por duas semanas.

\section{DISCURSOS EM RELAÇÃO: A TÔNICA DA AD}

"A finalidade do analista de discurso não é interpretar, mas compreender como um texto funciona, ou seja, como um texto produz sentidos" (ORLANDI, 2012, p. 19). Uma série de fatores incide sobre as interpretações - e eles não estão restritos à instância de produção do 
discurso: as condições inerentes à recepção, ou à leitura dos textos, também determinam os sentidos que serão atribuídos à mensagem.

Para a $\mathrm{AD}$, interessam os contextos imediatos em que o discurso é produzido e absorvido, além das delimitações históricas, sociais, culturais e ideológicas que possam tecer influências sobre o conteúdo. Importam ainda o sujeito que enuncia - enunciador - e aquele que atribui significados ao texto, chamado de coenunciador. Para a $\mathrm{AD}$, é fundamental que um discurso seja analisado não de forma fechada, em si mesmo, mas em relação a outros discursos. 'O 'sentido' de um texto, de uma frase, e, no limite, de uma palavra, só existe em referência a outros textos, frases ou palavras que constituem seu 'contexto' […]" (PÊCHEUX, 2014, p. 165).

A noção de interdiscurso pode contribuir para a compreensão dessa lógica, já que todo texto contém vestígios de textos anteriores. De acordo com Orlandi (2012, p. 59), "em sua definição, o interdiscurso é o conjunto de dizeres já ditos e esquecidos que determinam o que dizemos, sustentando a possibilidade mesma do dizer. Para que nossas palavras tenham sentido é preciso que já tenham sentido". As citações são exemplos clássicos da existência do interdiscurso; porém, nem sempre essa presença é evidente - muitas vezes pode se mostrar "esquecida" dada a naturalidade com que passa a operar em um determinado enunciado.

A presença do interdiscurso denota posições ideológicas adotadas pelo enunciador. Se o sujeito escolhe dizer de uma maneira - e não de outra - está selecionando sentidos que serão transmitidos e apagando outras possibilidades de dizer. Da mesma forma, a recepção, interpretação e compreensão de um discurso adquirem determinado sentido em detrimento de outros possíveis, porém, descartados.

Ainda nessa seara, convém introduzir a noção de dialogismo, conceito proposto por Bakhtin, em 1929. "Dialogismo significa que um discurso se constitui em oposição a outro. Portanto, ele é heterogêneo: um discurso mostra a si mesmo e seu contrário", explica Fiorin (2013, p. 64). Trata-se de um sentido construído a partir de múltiplas vozes (polifonia) e de caráter inconclusivo.

Esse viés aberto do discurso, defendido por Bakhtin, torna-se metodologicamente determinante para a $\mathrm{AD}$, pois o dialogismo só pode ser captado a partir da observação de discursos em oposição. “A relação dialógica é uma relação (de sentido) que se estabelece entre enunciados na comunicação verbal. Dois enunciados quaisquer, se justapostos no plano do sentido (não como objeto ou exemplo linguístico), entabularão uma relação dialógica" (BAKHTIN, 1997, p. 345-346). 
Enquadrar os textos selecionados sobre a Yahoo como jornalísticos e organizacionais constitui, a priori, um procedimento simplista diante da complexidade que envolve a tipologia de discursos. Esforços de classificação em gêneros, espécies ou tipos discursivos têm sido empreendidos por teóricos da $\mathrm{AD}$, demonstrando que a identificação de um texto com certas características de linguagem não é acessória para a condução da análise.

\section{TIPOLOGIA DE DISCURSOS: ELEMENTO FACILITADOR DA ANÁLISE}

Por que é importante enquadrar o discurso a ser analisado em um determinado tipo? A classificação tem uma função metodológica e permite ao analista atribuir algumas particularidades preconcebidas ao seu objeto de estudo. Dois critérios seriam fundamentais para a seleção da tipologia: a natureza do texto e o objetivo da análise.

A problematização das classificações discursivas passa pela noção de gêneros ${ }^{1}$. Bakhtin é um dos autores que trabalham esse enquadramento, alinhado à proposta de critérios institucionais e das esferas do conhecimento para fundamentar o conceito. Para ele, a utilização da língua está atrelada às atividades humanas, que acabam por definir o conteúdo temático, o estilo e a construção composicional do que é dito. "Qualquer enunciado considerado isoladamente é, claro, individual, mas cada esfera de utilização da língua elabora seus tipos relativamente estáveis de enunciados, sendo isso que denominamos gêneros do discurso" (BAKHTIN, 1997, p. 279, grifos do autor).

O filósofo reconhece a "extrema heterogeneidade" dos gêneros discursivos, que incluem desde os diálogos cotidianos até os textos literários, passando pelas diferentes formas de manifestações científicas, sociopolíticas, artísticas, entre outras. Para tentar facilitar a análise teórica dessa infinidade de discursos, ele propõe outra classificação: o gênero de discurso primário (ou simples) e o secundário (complexo). Como exemplo do primário, apresenta a réplica do diálogo cotidiano ou uma carta pessoal. A partir do momento em que essa réplica ou essa carta são absorvidas por um romance, por exemplo, elas passam a integrar um discurso secundário, mais elaborado. Ao serem incorporadas ao discurso literário, essas formas primárias perdem a conexão com a vida cotidiana: há uma mudança significativa na natureza do discurso.

\footnotetext{
${ }^{1}$ Pinto (1999) prefere chamar a variedade de gêneros discursivos de espécies de discursos, porém, sua fundamentação para essa escolha é apresentada de maneira superficial.
} 
Por admitir a coexistência entre sua tipologia e aquela que vincula os gêneros às atividades humanas, Bakhtin enxerga uma articulação irredutível entre os gêneros discursivos e o estilo dos enunciados. Por isso, pondera que "as mudanças históricas dos estilos da língua são indissociáveis das mudanças que se efetuam nos gêneros do discurso" (BAKHTIN, 1997, p. 285), ainda que reconheça a relativa estabilidade dos enunciados que formatam os gêneros.

Outro estudioso que se debruça sobre a questão é Maingueneau. Ele aponta para a utilidade dessa classificação tipológica, constatando que "para um locutor, o fato de dominar vários gêneros de discurso é um fator de considerável economia cognitiva" (MAINGUENEAU, 2004a, p. 63, grifo do autor). E exemplifica:

Graças ao nosso conhecimento dos gêneros do discurso, não precisamos prestar uma atenção constante a todos os detalhes de todos os enunciados que ocorrem à nossa volta. Em um instante somos capazes de identificar um dado enunciado como sendo um folheto publicitário ou como uma fatura e, então, podemos nos concentrar apenas em um número reduzido de elementos (MAINGUENEAU, 2004a, p. 64).

O linguista propõe duas categorias: gêneros conversacionais e instituídos (MAINGUENEAU, 2004b). De acordo com alguns estudiosos de sua obra, há uma aproximação entre a classificação sugerida por ele e por Bakhtin. Cavalcanti (2013) pondera que os gêneros conversacionais estariam para os primários, de Bakhtin, assim como os gêneros instituídos corresponderiam aos secundários. Com base nessas distinções de tipos e gêneros discursivos, este estudo adota a classificação apresentada inicialmente por Bakhtin, de gêneros identificados com atividades humanas - e que Maingueneau adapta para atividades sociais. Portanto, os gêneros de discursos jornalísticos e de discursos organizacionais evidenciam características próprias que tendem a facilitar o trabalho de AD.

Antes de introduzir a análise sobre o silenciamento, é reproduzida a seguir uma das matérias jornalísticas selecionadas para a análise de discurso envolvendo a Yahoo. Ela foi publicada no dia 25 de fevereiro de 2013 pela revista digital "Info Exame", da Editora Abril. Ao final, o texto reproduz, na íntegra, a tradução do memorando interno distribuído aos funcionários, um autêntico enunciado organizacional. 
Marissa Mayer elimina home office no Yahoo!

Por Barbara Ladeia, de Exame.com・ segunda, 25 de fevereiro de 2013

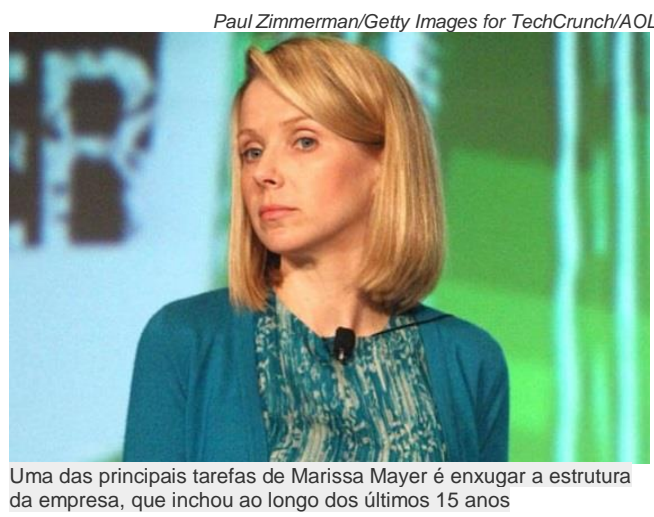

São Paulo - Na contramão das tendências em recursos humanos, o Yahoo! anuncia o fim do home office em todos os países onde atua. A partir de junho, todos os funcionários deverão trabalhar nos escritórios da empresa.

Em nota, divulgada a todos os funcionários na última sexta-feira, Jackie Reses, vicepresidente executiva de pessoas e desenvolvimento, afirmou que "velocidade e qualidade são muitas vezes sacrificadas quando se trabalha de casa".

Segundas intenções - No entanto, essa pode estar sendo mais uma das decisões de Marissa Mayer com a intenção de diminuir os custos operacionais da empresa, os quais cresceram muito nos últimos 15 anos.

Segundo a Business Insider, um dos efeitos colaterais dessa decisão seria a demissão voluntária daqueles que não pretendem se encaixar na nova regra da companhia. Embora não tenha mencionado demissões após ser empossada no cargo, uma das principais preocupações de Mayer seria reduzir os gastos.

Para isso, colocou Ken Goldman na posição de Chief Financial Officer (CFO), veterano da indústria de tecnologia. Segundo o analista na JMP Securities LLC, Erik Suppiger, em entrevista à Bloomberg, Goldman é conhecido no mercado por sua capacidade de corte de custos e melhoria da gestão de recursos.

Veja a tradução da nota enviada por Jackie Reses a todos os funcionários

"Ao longo dos últimos meses, introduzimos uma série de grandes benefícios e ferramentas para nos tornar uma empresa mais produtiva, eficiente e divertida. Com a introdução de iniciativas como FYI, Metas e PB\&J, queremos que todos participem na nossa cultura e contribuam para esse impulso positivo. De Sunnyvale a Santa Monica, Bangalore a Pequim acho que todos nós podemos sentir a energia e os zumbidos nos nossos escritórios. 
Para se tornar o melhor lugar para trabalhar, comunicação e colaboração serão importantes, por isso temos de estar trabalhando lado-a-lado. É por isso que é fundamental que estejamos todos presentes em nossos escritórios. Algumas das melhores decisões e ideias vêm de discussões no corredor e na cafeteria, vem de conhecer novas pessoas e das reuniões improvisadas. Velocidade e qualidade são muitas vezes sacrificadas quando se trabalha de casa. Nós precisamos ser um Yahoo!, e isso começa por estarmos fisicamente juntos.

A partir de junho, pedimos a todos os funcionários em home office para trabalhar nos escritórios do Yahoo!. Se isso impacta você, seu gestor já está ciente dos próximos passos. Para o resto de nós, que ocasionalmente têm de ficar em casa para esperar o rapaz da televisão a cabo, por favor, use o bom senso no espírito de colaboração. Ser um Yahoo não envolve apenas o seu trabalho cotidiano, mas também as interações e experiências que só são possíveis em nossos escritórios.

Obrigada a todos vocês, nós já fizemos um progresso notável como uma empresa - e o melhor ainda está por vir" (LADEIA, 2013).

\section{A DESCONTINUIDADE DO DITO E A PERSPECTIVA DO SILÊNCIO LOCAL}

A análise de discurso proposta requer uma abstração a respeito do silêncio. Ao menos em duas situações ele se mostra instigante no caso Yahoo - no momento em que a mídia se cala sobre a polêmica envolvendo o fim do home-office na empresa, justamente no período em que a regra deveria entrar em vigor, e quando a organização adota um discurso para justificar a decisão, elege argumentos que constroem um sentido com essa finalidade e acaba por silenciar outros.

No primeiro caso, não se pode falar em silenciamento absoluto, e sim em um silêncio substancial se comparado ao alvoroço midiático estabelecido por ocasião do anúncio da medida, entre fevereiro e maio de 2013. A magnitude conferida ao debate pelos veículos de comunicação especializados em negócios está fartamente registrada na internet, em sites de língua inglesa, portuguesa e espanhola, anunciando e repercutindo a polêmica deliberação da empresa.

Nenhum texto jornalístico abordando o assunto foi localizado por esta pesquisa durante a implantação da norma proibitiva, em junho daquele ano, nem nos meses subsequentes, como forma de avaliar os resultados. O fato de não terem sido encontradas novas matérias não exclui a possibilidade de que elas tenham sido produzidas. O que se pode inferir é que a eventual circulação, caso tenha ocorrido, foi relativamente restrita. Essa é a primeira situação de silêncio que será trabalhada teoricamente a partir de agora. 
Orlandi (2007) reposiciona a concepção do silêncio nos estudos da linguagem ao propor que, ao invés de pensá-lo como falta, seria conveniente vislumbrar a própria linguagem como excesso. Ou seja, a pesquisadora promove o silêncio à condição de figura discursiva e o afasta da posição quase automática de fundo. Na prática, confere a ele certo protagonismo, sugerindo uma análise a partir de sua face positiva.

Segundo ela, o silêncio é condição para o significado e "há um sentido no silêncio" (ORLANDI, 2007, p. 12). A tentativa de elevar o silêncio a uma categoria superior se justifica pelo entendimento da comunicação como modelo privilegiado/hegemônico na sociedade contemporânea. É como se o uso da linguagem verbal e não-verbal respondesse por um movimento existencial. O não-dizer e o não-manifestar-se incomodam, a ponto de o sujeito se tornar uma espécie de refém das referências simbólicas. Se a fala comunica, o silêncio idem.

A visão da linguística sobre o silêncio é apenas uma perspectiva de análise; a poética é outra. A psicanalista Juliana Hernandez recorreu a vários campos da cultura, inclusive a linguística, na tentativa de compreender o silêncio - ora apaziguador, ora insuportável relatado por uma paciente. Outras contribuições surgiram da própria psicanálise, da literatura, da religião, da filosofia e da matemática.

$\mathrm{Na}$ abordagem matemática, um dos significados do silêncio é equiparado ao algarismo zero. Da mesma forma como Orlandi pressupõe o silêncio como condição para o significado, “o zero é o enigma que envolve essa condição de possibilidade do um; o nada em que se abriga o mistério da origem, e que, como tal, precede o um" (KOVADLOFF, 2003, p. 100 apud HERNANDEZ, 2004, p. 144).

O estudo de Hernandez revela que o silêncio se apresenta sempre com um duplo estatuto, podendo exercer mais de uma função. Se o zero equivale ao nada, ao vazio, a autora explica que o silêncio no sentido de falta, de subtração, corresponderia, na matemática, ao menos um (-1). Estaria relacionado a uma retirada, uma ruptura perceptível apenas em relação a uma condição anterior.

A concepção de silêncio enquanto falta fundamenta o fenômeno observado na cobertura jornalística envolvendo a Yahoo, caracterizado pela descontinuidade. Contudo, antes de desenvolver a análise específica dessa situação discursiva, é válido conhecer as classificações atribuídas ao silêncio por Orlandi (2007, p. 24): 
[...] distinguimos entre: a) o silêncio fundador, aquele que existe nas palavras, que significa o não-dito e que dá espaço de recuo significante, produzindo as condições para significar; e b) a política do silêncio, que se subdivide em: b1) silêncio constitutivo, o que nos indica que para dizer é preciso não-dizer (uma palavra apaga necessariamente as "outras" palavras); e b2) o silêncio local, que se refere à censura propriamente (aquilo que é proibido dizer em uma certa conjuntura). Isso tudo nos faz compreender que estar no sentido com palavras e estar no sentido em silêncio são modos absolutamente diferentes entre si. E isso faz parte da nossa forma de significar, de nos relacionarmos com o mundo, com as coisas e com as pessoas.

O silêncio fundador, aquele que institui o espaço para a significação, representa, em última instância, uma concepção filosófica intrínseca ao silêncio. A compreensão do funcionamento das duas situações de silenciamento envolvendo a Yahoo se aproxima mais da política do silêncio, que estabelece fronteiras entre o dizer e o não-dizer. Não obstante a ideia de censura deva ser ressignificada, a noção de silêncio local se apresenta como compatível com a falta observada no discurso jornalístico.

A autora utiliza, na definição supracitada, o vocábulo "censura". Entretanto, ao detalhar o conceito de silêncio local ela substitui essa palavra pela expressão "interdição do dizer" (ORLANDI, 2007, p. 74) e coloca a censura como um exemplo dessa modalidade. O termo censura, no Brasil e em outros países da América Latina, carrega um sentido suficientemente institucionalizado, devido ao período do regime militar em que foi implantada como política pública de controle da liberdade de expressão.

$\mathrm{Na}$ atualidade, nota-se a existência de outras formas menos evidentes e mais sofisticadas de censura. Lima (2014) pontua, por exemplo, que a própria estrutura do mercado das empresas midiáticas implica um tipo de censura que afeta a capacidade crítica dos veículos de comunicação. As relações de poder que cercam a organização estudada e a mídia especializada são desconhecidas. Sabe-se, todavia, que toda situação de censura pressupõe movimentos de resistência. Entretanto, nas buscas realizadas para esta pesquisa, essa manifestação do opor-se à interdição não aparece. A única materialidade disponível, até o momento, é a da ausência.

Portanto, a partir de toda a articulação teórica esboçada, cabe, enfim, perguntar: o que significa o silêncio midiático envolvendo o caso Yahoo? Algumas inferências plausíveis, esboçadas antes e depois do lançamento da biografia sobre a empresa: 1) a organização não quis se manifestar e a mídia lhe assegurou esse direito; 2) haveria uma espécie de pacto deliberado entre organização e mídia para silenciar sobre o assunto, devido a interesses não 
sabidos; 3) o entusiasmo que motivou a mídia por ocasião do anúncio da medida teria se esgotado; 4) houve interesse por parte da mídia, porém, o acesso à informação sofreu algum tipo de bloqueio, o que teria desmotivado a continuidade na cobertura (improvável); 5) não haveria informação nova a ser divulgada, o que tornaria o noticiário repetitivo (improvável); 6) a mídia teria optado pelo silêncio ao, supostamente, ter tido acesso ao número reduzido de funcionários atingidos pelo fim do home-office, o que não justificaria o intenso debate criado por ela; 7) o silêncio teria sido proposital para restringir a discussão e evitar que outras organizações adotassem a mesma medida, o que iria contra interesses de grupos de comunicação.

Nota-se que, embora esses sentidos atribuídos ao silêncio sejam possíveis, alguns se mostram improváveis. No caso do item 4, impedimentos de acesso à informação costumam ser driblados pela prática do jornalismo investigativo. $\mathrm{O}$ enunciador midiático não dependeria apenas da fonte oficial - no caso, a empresa - para produzir seu material e poderia ter recorrido a fontes alternativas. $O$ quinto tópico também indica algum grau de improbabilidade, considerando que a instituição da medida - ou a eventual desistência de implantação por parte da empresa - representariam atos novos a serem noticiados, bem como a repercussão positiva ou negativa da adoção do trabalho nos escritórios. As duas últimas suposições (6 e 7) só puderam ser elaboradas a partir de informações disponibilizadas na biografia de Carlson.

Os eventuais sentidos atribuídos ao silêncio midiático não se aplicam ao silenciamento organizacional. Desde o início, a Yahoo se cala sobre a proibição do trabalho em casa. O portal Business Insider, que funciona como fonte de informação para sites de vários países, noticia em 23 de fevereiro de 2013 que o memorando interno divulgado naquela data era um documento confidencial (SMITH, 2013). O mesmo site publica, em 19 de abril daquele ano, a notícia intitulada "Marissa Mayer defende o fim do home-office" (CARLSON, 2013, tradução nossa), que não é fruto de entrevista com a dirigente nem de qualquer comunicado oficial da organização. A fala da CEO é obtida a partir de um discurso em uma conferência.

A Yahoo tem se mostrado uma organização fechada do ponto de vista da comunicação organizacional. De acordo com o conjunto de textos analisados, as únicas circunstâncias recentes que motivaram pronunciamentos oficiais foram os anúncios de desativação de escritórios na China e na Índia, comunicados por meio de nota à imprensa. Todas as outras matérias estudadas exibiam como origem outras fontes. 


\section{SILÊNCIO CONSTITUTIVO (OU O DIZER PARA NÃO DIZER)}

A segunda modalidade de silêncio observada nos discursos envolvendo a Yahoo se manifesta na escolha de sentidos para justificar a decisão da empresa e se enquadra na categoria de silêncio constitutivo. Nesse caso, o objeto deixa de ser o discurso jornalístico e passa a se constituir pelo discurso organizacional, mais precisamente o memorando interno. Contudo, a interdiscursividade se mantém como elemento indispensável para a AD.

"O silêncio constitutivo é o não-dito necessariamente excluído. Por aí se apagam os sentidos que se quer evitar [...]" (ORLANDI, 2007, p. 73). Para compreender o silêncio constitutivo é preciso, previamente, analisar o dito. A organização faz escolhas lexicais e semânticas - dentro de um contexto discursivo - para transmitir a seus funcionários a ideia de que trabalhar juntos, em situação de comunicação face a face, seria a melhor opção para a Yahoo naquele momento. Alguns enunciados resgatados do memorando traduzem essa noção: "De Sunnyvale a Santa Monica, Bangalore a Pequim - acho que todos nós podemos sentir a energia e os zumbidos nos nossos escritórios"; "Para se tornar o melhor lugar para trabalhar, comunicação e colaboração serão importantes, por isso temos de estar trabalhando lado-a-lado"; e ainda "Algumas das melhores decisões e ideias vêm de discussões no corredor e na cafeteria, vem de conhecer novas pessoas e das reuniões improvisadas. Velocidade e qualidade são muitas vezes sacrificadas quando se trabalha de casa."

$\mathrm{O}$ artifício textual escolhido para tentar convencer os funcionários a aderir à novidade busca associar a ideia do "físicamente juntos" (situação face a face, possível apenas nos escritórios) a elementos linguísticos carregados de positividade, como a repetição do adjetivo comparativo de superioridade "melhor": "o melhor lugar para trabalhar" e "as melhores decisões e ideias". Já a prática do trabalho em casa aparece vinculada à noção de "sacrifício" (termo que remete à privação e renúncia) de valores como qualidade e velocidade.

A forma de dizer adotada pela organização faz, ainda, um apelo à "identidade" dos funcionários, construída pelo uso do infinitivo do verbo "ser". "Nós precisamos ser um Yahoo!, e isso começa por estarmos fisicamente juntos" e "Ser um Yahoo não envolve apenas o seu trabalho cotidiano, mas também as interações e experiências que só são possíveis em nossos escritórios". Assim, o trabalho e o convívio face a face passam a compor o DNA de quem concorda em abandonar o home-office, ao mesmo tempo em que um novo 
silenciamento se institui: não há vestígios sobre o que caracterizava "ser um Yahoo" antes do anúncio da medida.

Ao se comunicar com os funcionários, a Yahoo incorpora, em geral, o pronome pessoal "nós", para se colocar no mesmo plano dos coenunciadores. O uso do "nós" enquadra na mesma perspectiva o sujeito falante e seus interlocutores, aproximando-os e até confundindo-os, propositadamente. Quando a organização, a vice-presidente e Marissa Mayer dizem "introduzimos uma série de grandes benefícios e ferramentas para nos tornar uma empresa mais produtiva, eficiente e divertida", elas estão compartilhando conquistas e instalando um ambiente de cumplicidade.

A mesma estrutura linguística produz essa possibilidade de leitura em "queremos que todos participem na nossa cultura", "todos nós podemos sentir a energia e os zumbidos nos nossos escritórios", "por isso [nós] temos de estar trabalhando lado-a-lado", "é fundamental que estejamos todos presentes em nossos escritórios", entre outras.

Porém, em um dado momento, a narrativa que transita entre o "nós" e o "nosso" sofre ruptura com a inserção do "você" e do "seu". Isso ocorre imediatamente após a convocação oficial para abandonar o trabalho em casa. "A partir de junho, pedimos a todos os funcionários em home office para trabalhar nos escritórios do Yahoo!. Se isso impacta você, seu gestor já está ciente dos próximos passos", continua o memorando. A cumplicidade se desfaz e um distanciamento se impõe na medida em que os "nossos" escritórios se transformam nos "escritórios da Yahoo", sugerindo uma suspensão, ainda que breve, do espírito colaborativo que vinha sendo construído.

Como se a frieza da narrativa tivesse sido notada a tempo e incomodasse o próprio enunciador, surge, na sequência imediata, uma tentativa obscura de reaproximação: "para o resto de nós...". Retorna o sujeito compartilhado, porém, não mais o "nós" puro e indissolúvel, mas o "nós" qualificado pelo "resto". Resto que pode significar sobra, sugerir certo desprezo e até mesmo relativizar o "nós" que "ocasionalmente têm de ficar em casa para esperar o rapaz da televisão a cabo". Esse "nós", certamente, exclui a cúpula da organização e os funcionários que não trabalham em casa. Aos outros - ou ao "resto" - a organização solicita o favor de usar "o bom senso no espírito de colaboração". Mais uma vez, o dialogismo suscita seu contrário (e implícito): faltaria bom senso àquele que trabalha em casa.

O antagonismo nós/você é retomado no penúltimo parágrafo do memorando, quando o enunciado define o "ser um Yahoo" a partir da oposição entre o "seu" trabalho cotidiano (em 
casa, esperando o rapaz da televisão a cabo) e "as interações e experiências que só são possíveis em nossos escritórios”.

Outra observação que merece atenção é o sentido otimista - e vago - produzido pelo enunciador ao final da mensagem, novamente a partir da dicotomia nós/você. Ao pronunciar "Obrigada a todos vocês", a(s) autora(s) se posiciona(m) em um plano distinto do lugar onde estão "vocês", dirigindo-se diretamente a esses interlocutores. No entanto, o "nós" é rapidamente resgatado: “nós já fizemos um progresso notável como uma empresa - e o melhor ainda está por vir". O enunciado intenciona concluir que, adotando a controversa medida, o futuro da empresa será promissor.

O discurso organizacional da Yahoo constitui, com propriedade, a defesa de algumas características das interações face a face que, de fato, são observadas na prática empresarial e na teoria sobre o tema. Porém, a definição de silêncio constitutivo exige que se questione: ao dizer tudo isso, o que a organização calou? Quais sentidos possíveis foram apagados? O que foi preciso dizer para silenciar o que não poderia e não deveria ter sido dito?

O enunciado da revista Info seria capaz, por si só, de indicar sentidos que deixaram de ser pronunciados no discurso organizacional. A "segunda intenção" da empresa de provocar demissões voluntárias a partir da impopularidade da medida seria um deles. $\mathrm{O}$ foco do discurso nas vantagens e benefícios das interações presenciais - utilizadas como estratégia de convencimento $^{2}$ - também silenciou as dificuldades que permeiam sua prática: os custos com deslocamentos, o tempo perdido no trânsito, a falta de habilidade cada vez mais comum para conversar frente a frente, entre outras. Foi exposta apenas a face positiva do contato presencial.

O que foi dito apaga, ainda, o sentido de uma possível crise da organização, que se transforma em dito meses depois, quando sites especializados começam a propagar informações sobre fechamentos de escritórios e demissões. Outros sentidos poderiam ser atribuídos ao silêncio constitutivo, todavia, esse tipo de análise jamais se esgota.

\section{CONSIDERAÇÕES}

Um primeiro ponto a se considerar é que a manifestação formal de organizações sobre as interações face a face não é comum. O tema, por si só, não conta com o mesmo apelo de

\footnotetext{
${ }^{2}$ Este estudo não questiona a legitimidade de qualquer organização utilizar argumentos de seu interesse para o convencimento ou engajamento de seus funcionários. Essa prática faz parte da rotina da comunicação organizacional.
} 
outros assuntos que inundam a cotidianidade das empresas, como o comportamento do mercado, as tecnologias, a política econômica, o desenvolvimento sustentável, entre outros. Falar publicamente sobre interações face a face indica que a organização olha para essa modalidade e tem algo relevante para comunicar sobre ela.

A concepção teórica da análise de discurso aplicada sobre esse material permite averiguar a forma como são construídos os sentidos, tanto na instância de produção (a empresa e a mídia) quanto na de recepção, levando em conta os gêneros em que se inserem e a instituição do silêncio, tão significante quanto a fala ao exprimir sentidos que deixam de ser ditos.

O discurso da Yahoo é emblemático no sentido de que uma empresa do ramo de tecnologia da informação, reconhecida mundialmente, defende com propriedade, perante seus funcionários, a prática do trabalho lado a lado. Não é difícil encontrar argumentos favoráveis à comunicação face a face - por sinal, a organização destaca apenas os pontos positivos dessa forma de interação: os aspectos que a tornariam inviável migram para a esfera do não-dito.

Diante do acompanhamento realizado entre 2013 e 2015, pode-se concluir que a Yahoo utilizou em seu memorando aos empregados argumentos favoráveis à comunicação face a face na tentativa de convencê-los a desistir do home-office. A intenção de mascarar prováveis demissões voluntárias é exposta no enunciado midiático durante o anúncio da medida. A análise interdiscursiva favorece, em um primeiro momento, o entendimento de que a empresa teria segundas intenções ao implementar a medida. Essa interpretação fica prejudicada, no entanto, no decorrer do episódio - tanto pelo surgimento de elementos novos (a biografia informando o pequeno número de funcionários afetados) quanto pela análise do enigmático silenciamento dos veículos especializados.

\section{REFERÊNCIAS}

BAKHTIN, Mikhail. Problems of Dostoevsky's poetics. Minneapolis: University of Minnesota Press, 1984. Disponível em: http://www.mohamedrabeea.com/books/book1_7956.pdf. Acesso em: 25 maio 2015.

Estética da criação verbal. 2. ed. São Paulo: Martins Fontes, 1997.

CARLSON, Nicholas. Marissa Mayer defends her work from home ban. Business Insider, New York, 19 Apr. 2013. Disponível em: <http://www.businessinsider.com/marissa-mayer-defends-her-workfrom-home-ban-2013-4>. Acesso em: 30 jul. 2017. 
CARLSON, Nicholas. Marissa Mayer: a CEO que revolucionou o Yahoo!. Tradução de Maria Silvia Mourão Netto. São Paulo: Benvirá, 2015.

CAVALCANTI, Jauranice Rodrigues. A presença do conceito de gêneros de discurso nas reflexões de D. Maingueneau. Linguagem em (Dis)curso, Tubarão, v. 13, n. 2, p. 429-448, maio/ago. 2013.

Disponível em: http://www.scielo.br/pdf/ld/v13n2/a11v13n2.pdf. Acesso em: 27 maio 2015.

FIORIN, José Luiz. Enunciação e comunicação. In: FIGARO, Roseli (Org.). Comunicação e análise do discurso. São Paulo: Contexto, 2013. p. 45-78.

HERNANDEZ, Juliana. O duplo estatuto do silêncio. Psicologia USP, v. 15, n.1-2, p. 129-147, jan./jun. 2004. Disponível em: http://www.scielo.br/pdf/pusp/v15n1-2/a16v1512.pdf. Acesso em 3 jun. 2015.

LADEIA, Barbara. Marissa Mayer elimina home-office no Yahoo. Info Exame, São Paulo, 25 fev. 2013. Disponível em: http://info.abril.com.br/noticias/carreira/marissa-mayer-elimina-home-office-noyahoo-25022013-34.shl. Acesso em: 25 ago. 2014.

LIMA, Venício A. de. A censura disfarçada. In: COSTA, Maria Cristina Castilho (Org.). A censura em debate. São Paulo: ECA/USP, 2014. p. 9-26.

MAINGUENEAU, Dominique. Análise de textos de comunicação. 3. ed. Tradução de Cecília P. de Souza-e-Silva e Décio Rocha. São Paulo: Cortez, 2004a. Disponível em: https://www.passeidireto.com/arquivo/2123382/127964024-maingueneau-dominique-maingueneauanalise-de-textos-de-comunicacao-pdf/2. Acesso em: 27 maio 2015.

. Diversidade dos gêneros de discurso. In: MACHADO. Ida Luzia; MELLO, Renato de (Orgs.). Gêneros: reflexões em análise do discurso. Belo Horizonte: NAD/FALE/UFMG, 2004b. p. 43-58.

ORLANDI, Eni Puccinelli. As formas do silêncio: nos movimentos dos sentidos. 6. ed. Campinas: Unicamp, 2007.

. Discurso e texto: formulação e circulação dos sentidos. 4 ed. Campinas: Pontes, 2012.

PÊCHEUX, Michel. Análise de discurso. 4. ed. Campinas: Pontes, 2014.

PINTO, Milton José. Comunicação \& discurso. São Paulo: Hacker Editores, 1999.

SMITH, Kevin. Here's the confidential memo Yahoo sent employees about working from home.

Business Insider, New York, 23 Feb. 2013. Disponível em: <http://www.businessinsider.com/yahooworking-from-home-memo-2013-2>. Acesso em: 30 jul. 2017.

Original recebido em: 31 de julho de 2017

Aceito para publicação em: 15 de dezembro de 2017

Ana Maria Dantas de Maio 
Doutora em Comunicação Social pela Universidade Metodista de São Paulo (2016); mestre em Comunicação pela Universidade Estadual Paulista, em Bauru-SP (2005); graduada em Comunicação Social, habilitação Jornalismo, pela UEL (Universidade Estadual de Londrina), em 1990; jornalista do Núcleo de Comunicação Organizacional (NCO) da Embrapa Pantanal de 2007 a 2017, em Corumbá (MS); jornalista do Núcleo de Comunicação Organizacional (NCO) da Embrapa Pecuária Sudeste, a partir de novembro de 2017, em São Carlos (SP).

Esta obra está licenciada sob uma Licença Creative Commons. 